\title{
Influence of sulphone therapy on lepromin reaction
}

\author{
G RAMU, U SENGUPTA \& K V DESIKAN \\ Central JALMA Institute for Leprosy, Taj Ganj, Agra-282 001, \\ India
}

Received for publication 20 November 1979

\begin{abstract}
Summary Sulphones administered in different doses were found to have a modulating effect on lepromin response in TT and BT cases. Twenty-six cases of TT and BT leprosy were initially lepromin tested and included in the study. Eight cases were given orally $100 \mathrm{mg}$ dapsone per day and nine cases were administered a single injection of acedapsone $225 \mathrm{mg}$. After 4 weeks all cases were retested with lepromin. The treatment was subsequently reversed so that the patients who received acedapsone earlier were placed on dapsone and those who had dapsone earlier were administered acedapsone. After a further 4 weeks the lepromin tests were again repeated. It was found that skin reaction to lepromin was significantly enhanced by small doses of sulphone and was depressed, although not significantly, by larger doses. Therefore, dapsone in full therapeutic doses may be usefully employed from the beginning in TT and BT cases with due care. It is also hypothesized that chemoprophylaxis with acedapsone might possibly enhance CMI against leprosy if already present.
\end{abstract}

\section{Introduction}

In an earlier study at this Institute a depresssion of phytohaemagglutinin (PHA) induced lymphocy te transformation was observed when human volunteers were administered dapsone in $100 \mathrm{mg}$ doses for one week (Sengupta et al, 1979a). ${ }^{1}$ Since leprosy patients receive dapsone continuously for long periods in different dosages, the observation on the effect of dapsone on lepromin reaction would be of considerable interest. A prospective study was therefore planned in which a lepromin test was conducted before and following dapsone therapy. It was also felt that different dosages of the drug might induce variation in lepromin reaction. As such the effect of dapsone in $100 \mathrm{mg}$ daily dosage and the effect of a single injection of acedapsone $(225 \mathrm{mg} / \mathrm{dose})$ on lepromin reaction were planned. The results of lepromin tests in patients treated by the 
two drugs were compared with each other as also with the results in patients without sulphone therapy.

\section{Patients and methods}

Twenty-six adult patients suffering from TT and BT leprosy attending the outpatient department of Central JALMA Institute for Leprosy, Agra, formed the subjects of the study. All but one were untreated. The duration of the disease varied from 2 months to 6 years. All the patients were examined clinically and bacteriologically. Biopsy specimens were obtained from representative skin lesions. The cases were classifed on the Ridley-Jopling Scale.

The patients were divided in three groups A, B and C. Group A received $100 \mathrm{mg}$ dapsone for 28 days. On day 29 one injection of acedapsone $(225 \mathrm{mg})$ was administered intramuscularly (IM). Group B was administered acedapsone $(225 \mathrm{mg}) \mathrm{IM}$ on inclusion to the study. After day 28 they received $100 \mathrm{mg}$ dapsone daily. Group $\mathrm{C}$ received placebo tablets one daily for 28 days. This group served as control.

Lepromin tests with standardized Dharmendra antigen (Sengupta et al, 1979) ${ }^{2}$ were conducted on the three groups at different intervals and readings taken as depicted in the flow diagram (Fig. 1). Dharmendra antigen is a chloroform-ether extracted bacilli from lepromas (Dharmendra, 1967) ${ }^{3}$ standardized by bacillary count (Sengupta et al., 1979b). ${ }^{2}$ The early reaction consisting of induration and erythema seen at 24 and $48 \mathrm{hrs}$ is measured at two
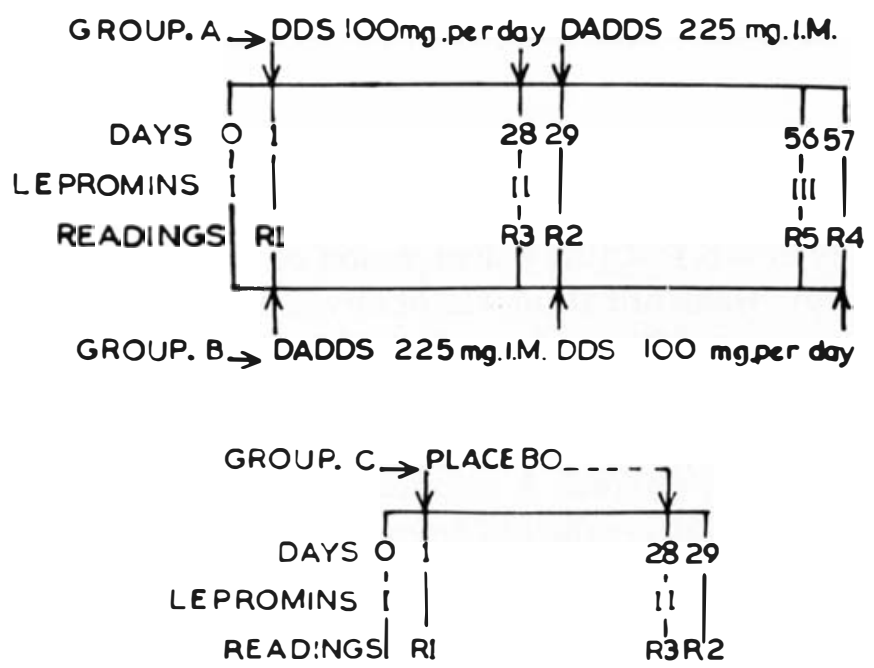

Figure 1. Treatment schedules and lepromin tests 
diameters at right angles and the average is recorded. The reaction wanes from $48 \mathrm{hrs}$ onwards. The late reaction consisting of an indurated nodule begins after about 7 days and reaches a maximum in 3 to 4 weeks. The diameter of the indurated nodule is measured at 3 weeks. The Dharmendra antigen gives a stronger early reaction than the Mitsuda - Hayashi antigen but gives a less pronounced late reaction. Group A was administered lepromin thrice. Lepromin I was administered on day 0, lepromin II on day 28 and lepromin III on day 56 . Reading $\mathrm{R} 1$ of the lepromin I is the early reaction prior to therapy. Reading $\mathrm{R} 2$ of lepromin II represents early reaction under dapsone therapy. Reading R3 of lepromin I represents late reaction following dapsone therapy. Reading R4 of lepromin III denotes early reaction following acedapsone therapy while reading R5 of lepromin II denotes late reaction following acedapsone therapy.

Group B was administered lepromin thrice as in group A. Lepromin I was administered on day 0, lepromin II on day 28 and lepromin III on day 56. Reading R 1 of lepromin I is the early reaction prior to therapy. Reading R 2 of lepromin II represents early reaction following acedapsone therapy while reading R3 of lepromin I represents late reaction following acedapsone therapy. Similarly reading R4 of lepromin III indicates early reaction following dapsone therapy while reading R5 of lepromin II indicates late reaction following dapsone therapy.

Group $\mathrm{C}$ received placebo tablets for 29 days. This group received lepromin only twice on day 0 and day 28 . Reading R 1 is the early reaction of lepromin I and reading $\mathrm{R} 3$ of lepromin $\mathrm{I}$ is the late reaction, both the readings being without the influence of sulphone. Reading R2 of lepromin II is an early reaction and this reading was taken to observe the possible effect, if any, of a repeated lepromin test.

\section{Results}

The results are presented in Tables 1, 2 and 3. It could be seen from Table 1 and Fig. 2 that following 4 weeks of administration of dapsone there was a diminution in the size of lepromin reaction, one case becoming even negative. On the other hand following the administration of acedapsone there was an enhancement in the intensity of the lepromin reaction. On statistical analysis, it was found that the depression following dapsone therapy is not significant. However, enhancement of the skin reaction following acedapsone was statistically significant $(\mathrm{p}<0.01)$.

Table 2 and Fig. 3 represent the situation when the sequence of therapy is reversed, patients receiving acedapsone first and dapsone subsequently. It could be seen that administration of acedapsone enhanced the intensity of lepromin reaction and this was found to be statistically significant $(p<0.05)$. Dapsone treatment brought down the intensity of reaction but it was found that the 
results are not statistically significant. It could thus be seen that acedapsone whether given initially or following a course of dapsone significantly enhanced lepromin reaction.

Table 1. Lepromin reaction following DDS therapy initially and DADDS subsequently (Group A)

\begin{tabular}{|c|c|c|c|c|c|c|c|}
\hline \multirow[b]{2}{*}{ Sl No } & \multirow[b]{2}{*}{ Reg No } & \multirow[b]{2}{*}{ Name } & \multirow{2}{*}{$\begin{array}{l}\text { Lepromin } \\
\text { reaction } \\
\text { before } \\
\text { treatment } \\
\text { in } \mathrm{mm} \\
\text { Early }\end{array}$} & \multicolumn{2}{|c|}{$\begin{array}{l}\text { Lepromin } \\
\text { reaction } \\
\text { following } \\
\text { DDS Therapy } \\
\text { in } \mathrm{mm}\end{array}$} & \multicolumn{2}{|c|}{$\begin{array}{c}\text { Lepromin } \\
\text { reaction } \\
\text { following } \\
\text { DADDS Therapy } \\
\text { in } \mathrm{mm}\end{array}$} \\
\hline & & & & Early & Late & Early & Late \\
\hline 1 & 10656 & $\mathrm{HL}$ & 10 & 0 & 0 & 20 & $\mathrm{U}$ \\
\hline 2 & 10762 & MP & 20 & 13 & 6 & 42 & $\mathrm{U}$ \\
\hline 3 & 10849 & ML & 22 & 16 & $\mathrm{U}$ & 37 & $\mathrm{U}$ \\
\hline 4 & 11007 & B & 18 & 20 & 10 & 23 & $\mathrm{U}$ \\
\hline 5 & 11014 & RS & 15 & 18 & 3 & 20 & $\mathrm{U}$ \\
\hline 6 & 10445 & $\mathrm{JN}$ & 20 & 12 & 3 & 20 & 7 \\
\hline 7 & 11174 & RB & 20 & 10 & 4 & 17 & $\mathrm{U}$ \\
\hline 8 & 10429 & $R L$ & 9 & 14 & 0 & 20 & $\mathrm{U}$ \\
\hline
\end{tabular}

$\mathrm{U}=$ Ulceration

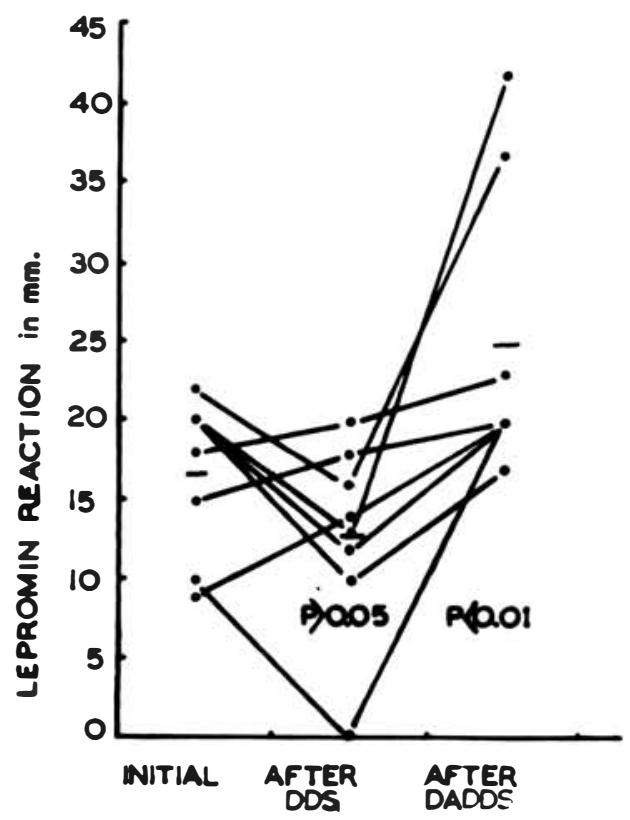

Figure 2. Influence on early lepromin reaction after DDS therapy and after subsequent DADDS therapy $(\cdot) \mathrm{mm}$. reaction of each patient. $(-)$ mean value. 
Table 2. Lepromin reaction following DADDS therapy initially and DDS subsequently (Group B)

\begin{tabular}{|c|c|c|c|c|c|c|c|}
\hline \multirow[b]{2}{*}{ Sl No } & \multirow[b]{2}{*}{ Reg No } & \multirow[b]{2}{*}{ Name } & \multirow[t]{2}{*}{$\begin{array}{l}\text { Lepromin } \\
\text { reaction } \\
\text { before } \\
\text { treatment } \\
\text { in mm } \\
\text { Early }\end{array}$} & \multicolumn{2}{|c|}{$\begin{array}{l}\text { Lepromin } \\
\text { reaction } \\
\text { following } \\
\text { DADDS } \\
\text { treatment } \\
\text { in } \mathrm{mm}\end{array}$} & \multicolumn{2}{|c|}{$\begin{array}{l}\text { Lepromin } \\
\text { reaction } \\
\text { following } \\
\text { DDS } \\
\text { treatment } \\
\text { in } \mathrm{mm}\end{array}$} \\
\hline & & & & Early & Late & Early & Late \\
\hline 1 & 10857 & $\mathrm{RS}$ & 10 & 25 & 6 & 18 & 4 \\
\hline 2 & 10748 & GS & 16 & 45 & 10 & 25 & 3 \\
\hline 3 & 11002 & D & 14 & 15 & 7 & 10 & 0 \\
\hline 4 & 10719 & RL & 18 & 28 & $\mathrm{U}$ & 20 & $\mathrm{U}$ \\
\hline 5 & 10346 & B & 14 & 30 & $\mathrm{U}$ & 13 & 2 \\
\hline 6 & 10759 & $\mathrm{~S}$ & 12 & 28 & $\mathrm{U}$ & 16 & 6 \\
\hline 7 & 11104 & $\mathrm{~J}$ & 17 & 29 & 10 & 16 & 2 \\
\hline 8 & 4477 & B & 10 & 25 & 6 & 18 & 4 \\
\hline 9 & 11145 & RN & 10 & 20 & 8 & 15 & 3 \\
\hline
\end{tabular}

$\mathrm{U}=$ Ulceration

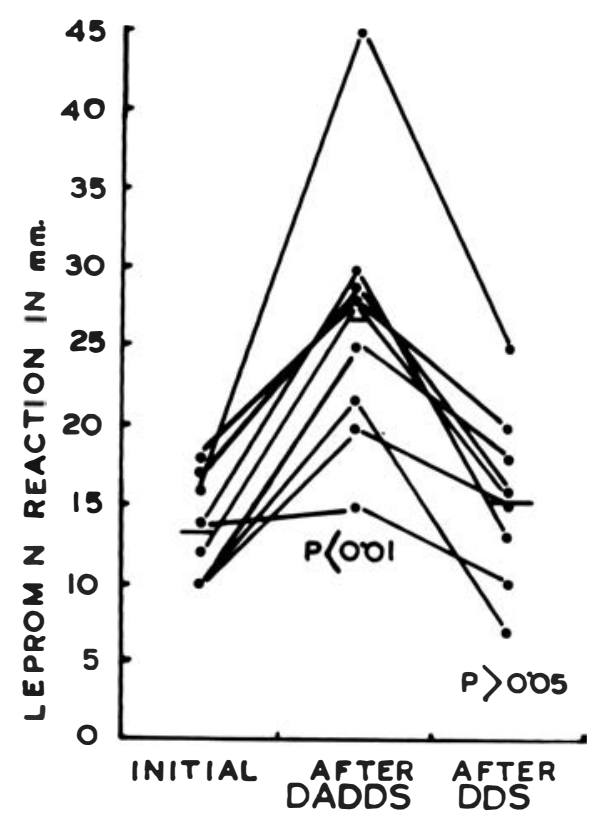

Figure 3. Influence on early lepromin reaction after DADDS therapy and after subsequent DDS therapy. $(\cdot) \mathrm{mm}$ reaction of each patient; $(-)$ mean value.. 
As could be seen in Tables 1 and 2 the late reaction following acedapsone therapy was quite severe resulting in ulceration in most of the cases. A peculiar phenomenon was observed in the cases treated with acedapsone. In many of the cases receiving this drug either initially or following dapsone therapy it was found that the second lepromin test after 4 weeks brought about an erythematous flare around the late lepromin nodule of the previous lepromin test resembling an exacerbated early response. This was not noticeable in cases receiving dapsone or placebo.

Table 3. Lepromin reaction in control subjects (Group C)

\begin{tabular}{|c|c|c|c|c|c|}
\hline \multirow[b]{2}{*}{$\mathrm{Sl}$} & \multirow[b]{2}{*}{ Reg } & \multirow[b]{2}{*}{ Name } & \multicolumn{2}{|c|}{$\begin{array}{l}\text { Results of } \\
\text { first lepromin } \\
\text { test }\end{array}$} & \multirow{2}{*}{$\begin{array}{c}\begin{array}{c}\text { Results of } \\
\text { repeated lepromin } \\
\text { test }\end{array} \\
\text { Early }\end{array}$} \\
\hline & & & Early & Late & \\
\hline 1 & 12437 & BD & 16 & 7 & 15 \\
\hline 2 & 12426 & $\mathrm{H}$ & 7 & 3 & 8 \\
\hline 3 & 12472 & $\mathrm{R}$ & 18 & 5 & 18 \\
\hline 4 & 12475 & CS & 22 & 8 & 20 \\
\hline 5 & 12334 & $\mathrm{D}$ & 12 & 4 & 12 \\
\hline 6 & 12111 & YMK & 13 & 5 & 14 \\
\hline 7 & 12333 & D & 13 & 4 & 13 \\
\hline 8 & 12468 & $\mathrm{KS}$ & 18 & 5 & 19 \\
\hline 9 & 12352 & $W$ & 5 & 0 & 10 \\
\hline
\end{tabular}

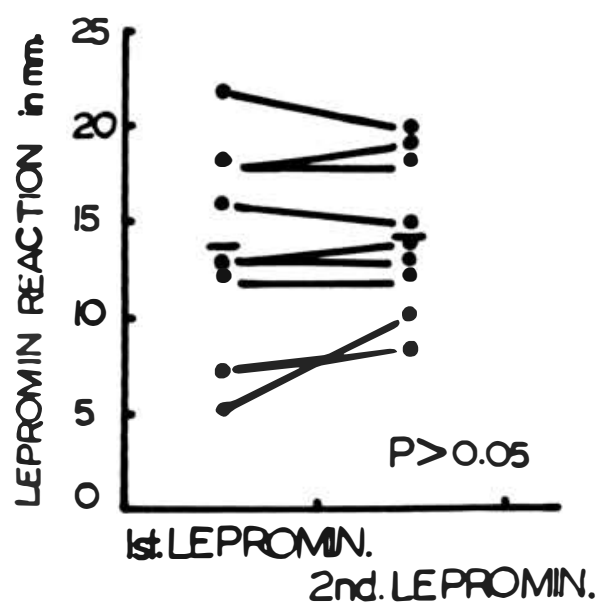

Figure 4. Effect of two lepromin tests on the size of early lepromin reaction. $(\cdot) \mathrm{mm}$. reaction of each patient. (-) mean value. 
The object of administration of placebo in the control group was to observe whether the second lepromin test had a boosting effect on the lepromin response. It could be seen in Fig. 4 and Table 3 that earlier lepromin injection does not influence the response to the latter.

\section{Discussion}

The results of the study show that the intensity of lepromin test is influenced by administration of sulphone. There is a depression by the therapeutic dose of $100 \mathrm{mg}$ daily. However, this was not statistically significant. Doses higher than $100 \mathrm{mg}$ were not tried. On the other hand, sulphones in small doses were found to stimulate the lepromin test. Acedapsone, $225 \mathrm{mg} \mathrm{I} \mathrm{M}$ administered in a single dose releases $2.5 \mathrm{mg}$ daily into the blood stream. With such a small dosage the lepromin response was found to be significantly heightened. The comparison was made on the same patients who first received dapsone and were subsequently switched over to acedapsone or vice-versa. Individual variations were thus ruled out by repeating the test on a separate control group without treatment with sulphone. The conclusions therefore bear testimony to the influence of sulphone in different doses upon the lepromin test.

The implications of these findings on sulphone therapy need to be considered. Although the optimum recommended dose is $10 \mathrm{mg}$ per $\mathrm{kg}$ body weight per week, which works out to $100 \mathrm{mg}$ per day for the adults, much smaller doses are frequently used. For example, it has been a practice to start therapy with a small doze (Dharmendra, 1967; ${ }^{3}$ Bryceson and Pfaltzgraff, 1973). ${ }^{4}$ Jopling $(1971)^{5}$ advises a small dose in tuberculoid and borderline cases since, according to him, reactions could be precipitated in these cases with the recommended doses. Further, it is an accepted practice to withhold the drug during reaction and-administer in small graded dosage after its subsidence. It is thus evident that sulphones are administered in different doses and the possible influence of such varied doses on the immune system deserve a careful study.

In view of the results of the present study it would appear that the sulphones have a modulating effect on the immune system. In vitro studies of Beiguelman and Pisani (1974) ${ }^{6}$ and of Sengupta et al (1979) ${ }^{1}$ have shown the depressive effect of dapsone to PHA-induced blastogenesis. If these in vivo and in vitro tests indicate cell-mediated immunity (CMI), it would appear that dapsone in high doses depresses CMI, while small doses would stimulate it. There is clinical evidence that TT and BT reactions are correlated with the increase in delayed hypersensitivity. The results of the present study would indicate that dapsone in normal clinical doses would be beneficial, and small doses might have a deleterious effect. Barnetson et al (1976) ${ }^{7}$ have presented some evidence that $1-2 \mathrm{mg}$ per $\mathrm{kg}$ body weight, might prevent reaction in 
borderline cases. The results of the present study support the view of some of the workers that sulphone should not be discontinued or reduced during reaction. However, it needs to be emphasized that treatment during reaction is to be viewed very carefully in view of the risk of precipitating nerve damage and deformity. Physicians should proceed cautiously while interpreting the results of experimental observations.

Another important implication of the present study is that if small doses have an enhancing effect on skin delayed hypersensitivity the use of acedapsone in the chemoprophylaxis of leprosy might have an additional advantage. In addition to its inhibitory effect on Mycobacterium leprae it could also have a boosting effect on the immunity of the host.

\section{References}

1 Sengupta U, Ghei SK, Venkatesan K, Bharadwaj VP. In vivo effect of DDS on phytohaemagglutinin (PHA) induced lymphocyte transformation cultures in normal healthy volunteers. Int J Lepr, 1979, 47, 167.

2 Sengupta U, Ramu G, Desikan KV. Assessment of Dharmendra antigen II. Standardization of the antigen. Lepr India, 1979, 51, 316.

3 Dharmendra. In: Notes on Leprosy, published by Ministry of Health, Government of India, 1967, pp. 151.

4 Bryceson A, Pfaltzgraff RE. In: Leprosy for Students of Medicine, 1973, pp. 74.

5 Jopling WH. In: Handbook of Leprosy. London: William Heinemann Medical Books Ltd., 1971, pp. 52.

6 Beiguelman B, Pisani RCB. Effect of DDS on phytohaemagglutinin induced lymphocyte transformation. Int J Lepr, 1974, 42, 412.

7 Barnetson R Stc, Pearson JMH, Rees RJW. Evidence for prevention of borderline leprosy reactions by dapsone. Lancet, 1976, 2, 1171. 